\title{
Experimental verification of the numerical model of a reinforced concrete arch
}

\author{
Barbara Markiewicz ${ }^{1,{ }^{*}}$, Grzegorz Piątkowski ${ }^{1}$, tukasz Szyszka ${ }^{1}$, and Dominika Ziaja ${ }^{1}$ \\ ${ }^{1}$ Rzeszow University of Technology, The Faculty of Civil and Environmental Engineering and \\ Architecture, Poznanska 2, 35-084 Rzeszow, Poland
}

\begin{abstract}
The paper presents numerical and experimental dynamic analysis of the reinforced concrete arch. The measurement of the accelerations at various points of the structure as a response to the force (single input-multiple output approach) was made. Dynamic response of the concrete arch has been measured by piezoelectric accelerometers and signals have been recorded by multi-channel LMS SCADAS Mobile recorder. As a result of the measurements frequencies and mode shapes have been determined. ADINA program has been used for building of numerical models. The static scheme of the arch (the stiffness of the supports) has been updated using the genetic algorithms (GA) available in MATLAB to obtain the results, which correspond to dynamic testing. Two similarity criteria have been considered: the mean squared error (MSE) between frequencies and the Modal Assurance Criterion (MAC) for forms comparison. In additional example, the Young's modulus has been also optimized.
\end{abstract}

\section{Introduction}

Nowadays we can clearly observe the increase of the importance of dynamic analysis in structural design. The sensitivity to dynamic loads, i.e. wind pressure, earthquake, machine operation, road and rail traffic, is of great importance. These loads, even at small values, can endanger the safety and durability of a structure, especially in the case of slender and light constructions. Dynamic analysis consider not only the stiffness, but also the mass of the structure, thus giving a more accurate information of the behaviour of the structure.

What is more, dynamic analysis can be successfully used in structural assessment procedures. Existence of a structural damage leads to modification of modal parameters (natural frequencies, mode shapes and modal damping values). Changes in the modal parameters may not be the same for each mode. They depend on the nature, location and severity of the damage. Thus, an analysis of periodical data from dynamic testing can be used in monitoring of structural condition [1].

Going further, structural monitoring and testing procedures for the dynamic characterization of a structure are essential tools for the calibration of numerical models. The process of matching parameters of numerical model to the target response, so called

\footnotetext{
*Corresponding author: dziaja@prz.edu.pl
} 
model updating, implements the optimization to identify parameters that minimize function representing the distance between the measured data and the predicted data [2].

The most popular method is a gradient-based optimization strategy. For more specific results response surface modelling (RSM), particle swarm optimization (PSO), Monte Carlo optimization, and genetic algorithms (GA) can be used. Recently, various type of the Artificial Neural Networks (ANNs) have been increasingly used as a model updating tool, especially in case of updating of computational models on the basis of limited number of measurement data [3].

In this paper numerical and experimental dynamic analysis of the reinforced concrete arch were presented. The dynamic response of the concrete arch to the impact force has been measured by accelerometers and as a result of the measurements frequencies and mode shapes have been determined. The aim of the study was to find the static scheme of numerical model, for which the experimental results could be considered as corresponding. The static scheme of the arch (the stiffness of the supports) and additionally the Young's modulus have been optimized using the genetic algorithms (GA) available in MATLAB environment. The considered similarity criteria included frequencies and modal shapes (MAC) comparison.

\section{Description of the tested structure}

The tested structure is a reinforced concrete arch of a span of about $10 \mathrm{~m}$ and rise above $2 \mathrm{~m}$. The exact dimensions of the arch and its cross-section are shown in Figure 1.
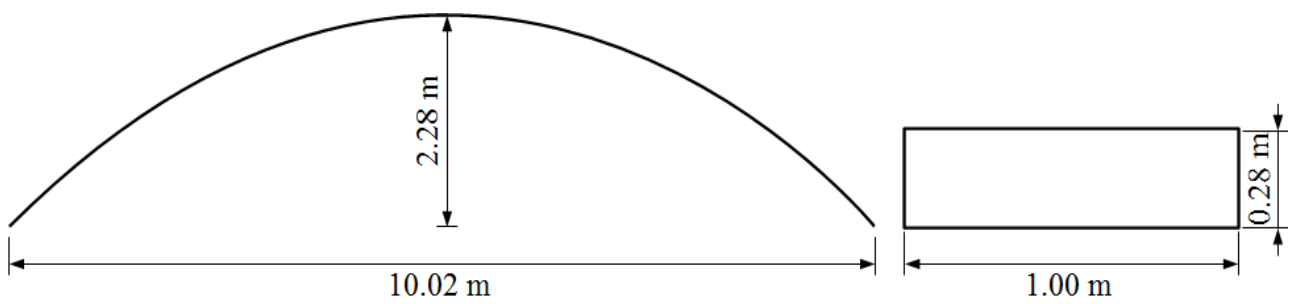

Fig. 1. Dimensions of the arch and its cross-section.

The arch is essentially a curved beam, which great advantage is the possibility of all sections of the arch to be under simple compression with no tension. This is especially important in case of reinforced concrete construction.

Arches are used for centuries for structures, where long spans are desired, in roofs of such buildings as hangars, auditoriums, gymnasiums and to support bridge decks. However, it can be noticed that they are also one of the key components for modern complex structures [4].

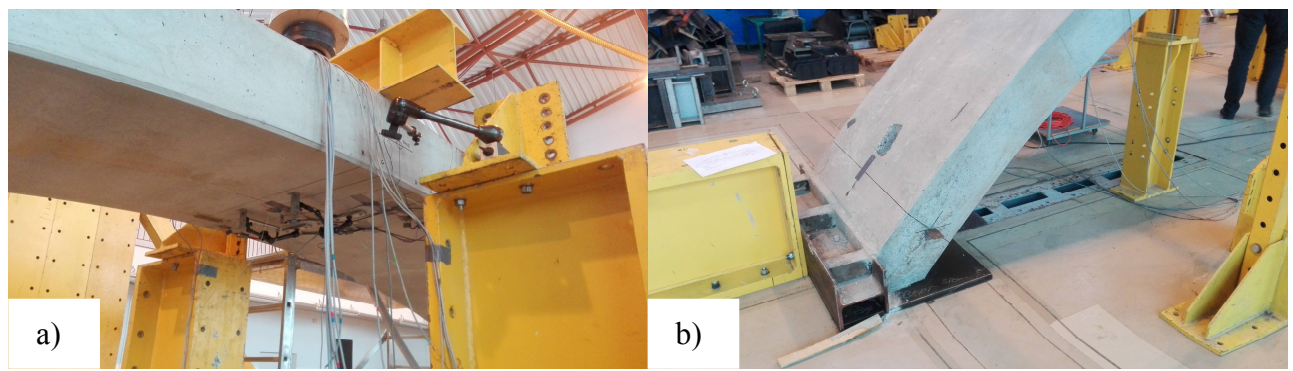

Fig. 2. Fragments of the concrete arch: a) the beam element on the top, b) support. 


\section{Experimental measurements}

The measurements shown in this paper are only addition for bigger project realised in Rzeszow University of Technology. The main aim of the project is not an object of this paper, so the description of it has been omitted.

The classical modal analysis has been used, which is based on the measurement of the existing force and accelerations at various points of the structure as a response to this force (SIMO). Impact excitation has been generated by PCB Piezotronics modal hammer in point shown in Fig. 3, in the vertical direction.

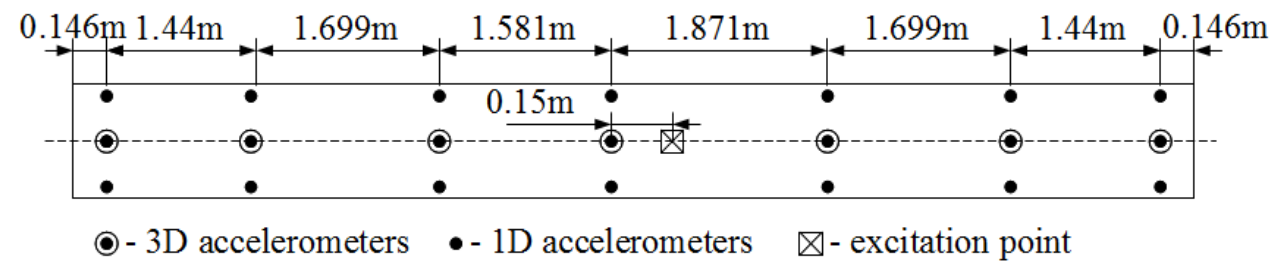

Fig. 3. Measurement points location.

Dynamic response of the concrete arch has been measured by 21 piezoelectric accelerometer sensors (two types of sensors were used: 3D and 1D). The 3D measurement points ( 7 sensors) have been located on the upper surface of the arch on its axis. The 1D measurement points have been placed $2 \mathrm{~cm}$ from edges on the both side of the structure (14 sensors) to obtain a torsional form optionally. In this study, only 3D sensors data was taken into account, because only the forms in the plane were analysed. Multi-channel signal recorder Scadas Mobile's LMS International has been used in measurements. Signals in the frequency range $0-256 \mathrm{~Hz}$ with a resolution of $0.125 \mathrm{~Hz}$ have been recorded during acceleration measurements. Recorder software allows for the classical experimental modal analysis including estimation of poles using Polymax method and visualization of the results. As a result of the measurements frequencies and vibration modes have been determined.

\section{Model updating}

\subsection{Numerical models}

The ADINA program has been used for building of numerical models. Preliminary estimates of the dynamic properties are based on the simplest numerical model. The model of a studied arch is a frame element with three degrees of freedom to analyse only the in plane shape modes.

Because the method of fixing of the arch was ambiguous, see Fig. 2 b), four types of boundary conditions have been considered: clamped (NUM1), pinned at both ends (NUM2), simple support (NUM3) and clamped with one unfixed horizontal translation (NUM4), see Fig. 4. These four support variants were analysed to determine the range of expected values of the frequency and to observe dynamic behaviour of the arch depending on enabling the support to slide and/or rotate. The cases with additional ' $\mathrm{M}$ ' include concentrated mass located on the top of the arch. This is the mass of the traverse beam made of the HEA240 profile, of $1.5 \mathrm{~m}$ length, which is $90 \mathrm{~kg}$, see Fig. 2 a).

The data used in calculations: the Young's modulus equal to $36 \mathrm{GPa}$, shear modulus $15 \mathrm{GPa}$ and specific weight $24.53 \mathrm{kN} / \mathrm{m}^{3}$. 

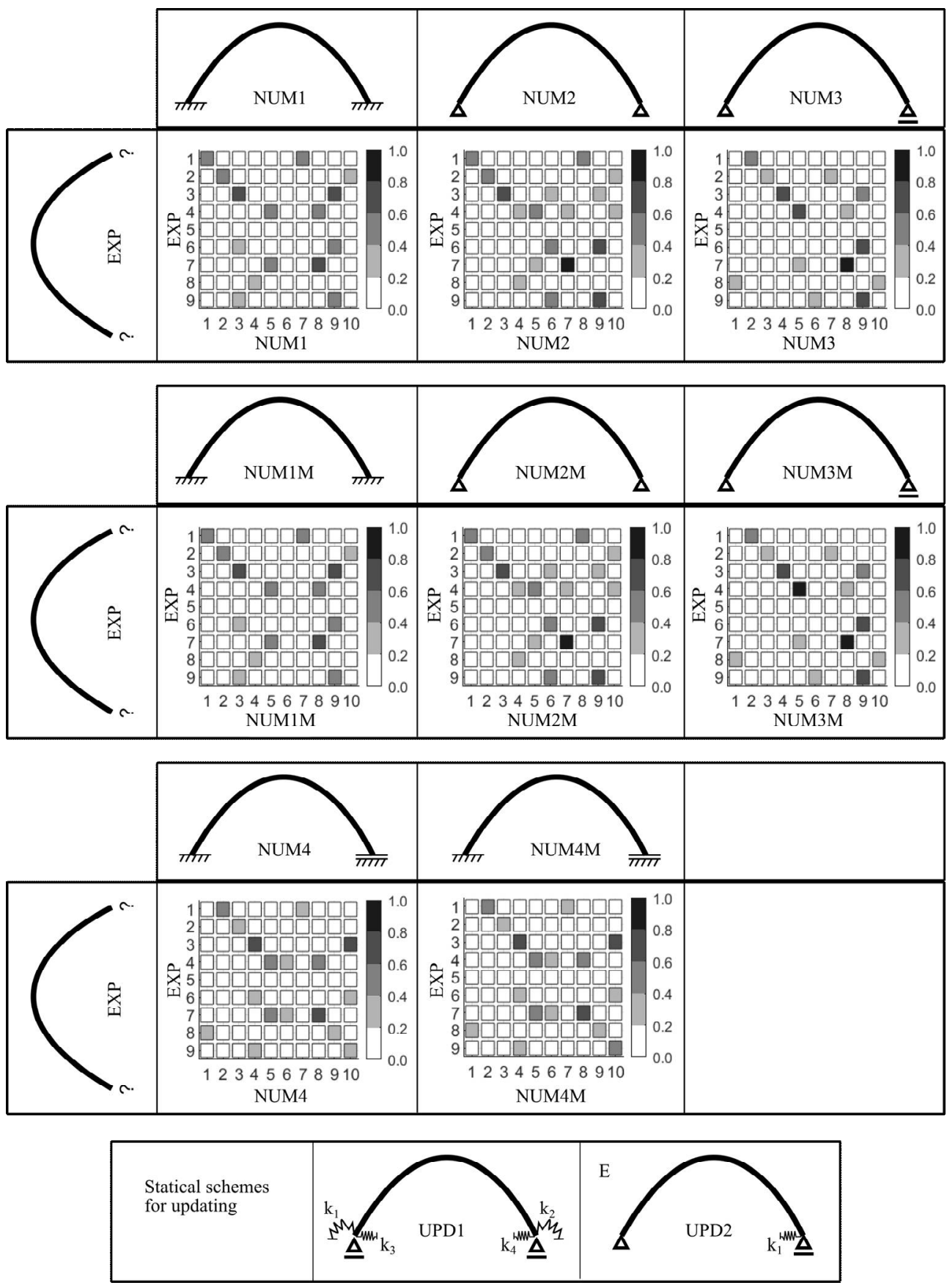

Fig. 4. The analysed schemes and correlation matrices between the analysed numerical and experimental forms

\subsection{Similarity criteria}

The eigenfrequencies and eigenforms of numerical models have been analysed and compared with modal frequencies and modal forms of a physical model. 
Table 1. Frequencies of analysed models $[\mathrm{Hz}]$

\begin{tabular}{|c|c|c|c|c|c|c|c|c|}
\hline EXP & NUM1 & $\begin{array}{c}\text { NUM1 } \\
\text { M }\end{array}$ & NUM2 & $\begin{array}{c}\text { NUM2 } \\
\text { M }\end{array}$ & NUM3 & NUM3 & NUM4 & $\begin{array}{c}\text { NUM4 } \\
\text { M }\end{array}$ \\
\hline 16.32 & 20.82 & 20.77 & 12.43 & 12.40 & 3.33 & 3.30 & 7.32 & 7.25 \\
\hline 32.16 & 38.51 & 37.68 & 28.80 & 28.28 & 13.82 & 13.77 & 22.05 & 21.98 \\
\hline 66.81 & 72.02 & 72.02 & 56.21 & 56.21 & 33.49 & 33.13 & 45.59 & 45.06 \\
\hline 103.32 & 80.73 & 80.72 & 77.58 & 77.52 & 57.95 & 57.94 & 72.96 & 72.96 \\
\hline 112.73 & 115.74 & 114.11 & 103.77 & 102.24 & 92.54 & 91.69 & 110.35 & 109.85 \\
\hline 145.94 & 149.34 & 149.03 & 127.03 & 126.87 & 115.05 & 114.26 & 118.14 & 116.74 \\
\hline 189.72 & 190.11 & 188.86 & 180.30 & 178.85 & 143.33 & 143.19 & 161.78 & 161.77 \\
\hline 230.82 & 206.57 & 204.74 & 189.77 & 188.64 & 180.54 & 179.07 & 205.53 & 203.83 \\
\hline 246.57 & 266.95 & 266.79 & 241.27 & 240.83 & 238.89 & 238.75 & 257.20 & 255.08 \\
\hline- & 322.74 & 319.37 & 290.43 & 287.18 & 257.29 & 254.98 & 269.19 & 268.97 \\
\hline
\end{tabular}

In Table 1 the obtained following frequencies of analysed models have been listed. In column 'EXP' the experimental frequencies are listed and the remaining columns are numerical frequencies for various support schemes described before. The similarity of the forms have not been considered in Table 1. As a similarity criterion of the frequencies the percentage difference has been used, calculated as in formula:

$$
\Delta f_{\text {ine }}=\frac{f_{\text {in }}-f_{\text {ie }}}{f_{\text {ie }}} \cdot 100 \%
$$

where: $\Delta f_{\text {ine }}$ - the percentage difference between numerical and experimental the $\mathrm{i}$-th frequency values, $f_{i n}$ - the $\mathrm{i}$-th frequency obtained in numerical simulations, $f_{i e}-$ the $\mathrm{i}$-th frequency measured during dynamic testing.

And to asses compatibility of the numerical models and experimental model based only on the frequencies values the mean squared error (MSE) has been used, according to [5] computed as:

$$
e r r=\sum_{m}\left(f_{i n}-f_{i e}\right)^{2}
$$

where: $e r r$ - the mean squared error, $m$ - number of identified frequencies ( 9 in this case).

The similarity of obtained mode shapes has been not only visually assessed, but also parametrically using the Modal Assurance Criterion (MAC). The correlation between the vectors describing modal shapes obtained in test and numerical eigenvectors for FEM models is accomplished by means of the MAC value [6]:

$$
\operatorname{MAC}(i, j)=\frac{\left(\Psi_{i}^{n T} \Psi_{j}^{e}\right)^{2}}{\left(\Psi_{i}^{n T} \Psi_{i}^{n}\right) \cdot\left(\Psi_{j}^{e T} \Psi_{j}^{e}\right)}
$$

where: index $i$ - number of mode of numerical model (n), index $j$ - number of mode of physical model (e).

According to information in [5] and [6]: $0<\mathrm{MAC}<1,1$ means full fit, 0 means no correlation between the mode shapes. In practice, full adjustment of numerical and experimental forms turns out to be impossible and MAC $>0.8$ is considered to be in good agreement.

Figure 4 shows the correlation matrices for the analysed numerical and experimental forms. The numbers represent successive forms corresponding to the frequencies listed in Table 1. The value of the MAC coefficient between each of the two forms is symbolically represented by a square located in column and row marked with the numbers of the compared mode shapes, in the appropriate colour, according to the scale shown on the right.

Table 2 shows the matching frequencies in term of the similarity of mode shapes, which the MAC factor exceeded the value of 0.5 . The similarity criterion was lowered, because it 
was not possible to obtain satisfactory similarity of all forms (MAC >0.8). In Table 2 and Table 3 ' $\mathrm{N}$ ' means number of the mode.

Table 2. Comparison of experimental and numerical frequencies in term of mode shape $[\mathrm{Hz}]$

\begin{tabular}{|c|c|c|c|c|c|c|c|c|c|c|c|}
\hline EXP & \multicolumn{3}{|c|}{ NUM1 } & \multicolumn{2}{|c|}{ NUM1M } & \multicolumn{3}{|c|}{ NUM2 } & \multicolumn{3}{|c|}{ NUM2M } \\
\hline $\begin{array}{c}\mathbf{f} \\
{[\mathbf{H z}]}\end{array}$ & $\begin{array}{l}\mathbf{N} \\
{[-]}\end{array}$ & $\begin{array}{c}\mathbf{f} \\
{[\mathrm{Hz}]}\end{array}$ & $\begin{array}{c}\text { МAC } \\
{[-]}\end{array}$ & $\begin{array}{c}\mathbf{f} \\
{[\mathrm{Hz}]}\end{array}$ & $\begin{array}{c}\text { МAC } \\
{[-]}\end{array}$ & $\begin{array}{l}\mathbf{N} \\
{[-]}\end{array}$ & $\begin{array}{c}\mathbf{f} \\
{[\mathrm{Hz}]}\end{array}$ & $\begin{array}{c}\text { MAC } \\
{[-]}\end{array}$ & $\begin{array}{l}\mathbf{N} \\
{[-]}\end{array}$ & $\begin{array}{c}\mathbf{f} \\
{[\mathrm{Hz}]}\end{array}$ & $\begin{array}{c}\text { MAC } \\
{[-]}\end{array}$ \\
\hline 16.32 & 1 & 20.82 & 0.562 & 20.77 & 0.561 & 1 & 12.43 & 0.501 & 1 & 12.40 & 0.501 \\
\hline 32.16 & 2 & 38.51 & 0.585 & 37.68 & 0.586 & 2 & 28.80 & 0.576 & 2 & 28.28 & 0.576 \\
\hline 66.81 & 9 & 266.95 & 0.658 & 266.79 & 0.662 & 3 & 56.21 & 0.679 & 3 & 56.21 & 0.679 \\
\hline 103.32 & 5 & 115.74 & 0.595 & 114.11 & 0.594 & - & - & - & - & - & - \\
\hline 112.73 & - & - & - & - & - & - & - & - & - & - & - \\
\hline 145.94 & - & - & - & - & - & 9 & 241.27 & 0.658 & 9 & 240.83 & 0.659 \\
\hline 189.72 & 8 & 206.57 & 0.721 & 204.74 & 0.717 & 7 & 180.30 & 0.920 & 7 & 178.85 & 0.919 \\
\hline 230.82 & - & - & - & - & - & - & - & - & - & - & - \\
\hline 246.57 & - & - & - & - & - & 9 & 241.27 & 0.620 & 9 & 240.83 & 0.626 \\
\hline EXP & \multicolumn{3}{|c|}{ NUM3 } & \multicolumn{2}{|c|}{ NUM3M } & \multicolumn{3}{|c|}{ NUM4 } & \multicolumn{3}{|c|}{ NUM4M } \\
\hline $\begin{array}{c}\mathbf{f} \\
{[\mathbf{H z}]}\end{array}$ & $\begin{array}{l}\mathbf{N} \\
{[-]}\end{array}$ & $\begin{array}{c}\mathbf{f} \\
{[\mathrm{Hz}]}\end{array}$ & $\begin{array}{c}\text { MAC } \\
{[-]}\end{array}$ & $\begin{array}{c}\mathbf{f} \\
{[\mathrm{Hz}]}\end{array}$ & $\begin{array}{c}\text { МAC } \\
{[-]}\end{array}$ & $\begin{array}{l}\mathbf{N} \\
{[-]}\end{array}$ & $\begin{array}{c}\mathbf{f} \\
{[\mathbf{H z}]}\end{array}$ & $\begin{array}{c}\text { MAC } \\
{[-]}\end{array}$ & $\begin{array}{l}\mathbf{N} \\
{[-]}\end{array}$ & $\begin{array}{c}\mathbf{f} \\
{[\mathrm{Hz}]}\end{array}$ & $\begin{array}{c}\text { MAC } \\
{[-]}\end{array}$ \\
\hline 16.32 & 2 & 13.82 & 0.527 & 13.77 & 0.527 & 2 & 22.05 & 0.550 & 2 & 21.98 & 0.550 \\
\hline 32.16 & - & - & - & - & - & - & - & - & - & - & - \\
\hline 66.81 & 4 & 57.95 & 0.700 & 57.94 & 0.700 & 10 & 269.19 & 0.692 & 10 & 268.97 & 0.697 \\
\hline 103.32 & 5 & 92.54 & 0.792 & 91.69 & 0.808 & - & - & - & - & - & - \\
\hline 112.73 & - & - & - & - & - & - & - & - & - & - & - \\
\hline 145.94 & 9 & 238.88 & 0.622 & 238.75 & 0.617 & - & - & - & - & - & - \\
\hline 189.72 & 8 & 180.54 & 0.906 & 179.07 & 0.908 & 8 & 205.53 & 0.714 & 8 & 203.83 & 0.711 \\
\hline 230.82 & - & - & - & - & - & - & - & - & - & - & - \\
\hline 246.57 & 9 & 238.88 & 0.668 & 238.75 & 0.672 & - & - & - & - & - & - \\
\hline
\end{tabular}

Considering the values of frequencies collected in Table 1, and lack of similarity for most of modal shapes, it was clear, that none of the proposed schemes correctly describe the examined model. Two new schemes were proposed with various rigidity of supports (see UPD1 and UPD2 on Fig. 4). The stiffness of supports were the purpose subject of model updating.

\subsection{Optimization tools and objective functions}

For optimization the genetic algorithms (GA) available in the MATLAB environment in the Global Optimization Toolbox [7] have been used. The variables of optimization were stiffness (k1, k2, k3, k4 presented in Fig. 4) and in the second case k1 stiffness (horizontal one on the right side) and the Young's modulus. Each time, despite the different number of updated parameters, the maximum generation number of 100 has been set as one of the 
criteria to stop the optimization process. The number of individuals in each population was 50 .

During updating two object functions (OF1 and OF2) have been used:

$$
\begin{gathered}
\text { OF } 1=\sum_{i=1}^{4}\left(f_{i n}-f_{i e}\right)^{2}, \\
O F 2=\sum_{i=1}^{4}(1-\operatorname{MAC}(i, i))
\end{gathered}
$$

where: $f_{\text {in }}$ - frequency obtained in numerical simulations, $f_{i e}$ - frequency measured during dynamic testing, $M A C$ - coefficient describing similarity between numerical and experimental frequencies.

\section{Optimization results}

For the considered variants (various support schemes and different target functions described in Paragraph 4), the model optimization/updating procedure was repeated twenty times, the results were analysed and averaged. A summary of the obtained results is given in Table 3. The application of the OF2 function in UPD1M case did not give a definite solution, therefore the results were not presented in the table.

Table 3. Comparison of experimental and obtained from optimization frequencies $[\mathrm{Hz}]$

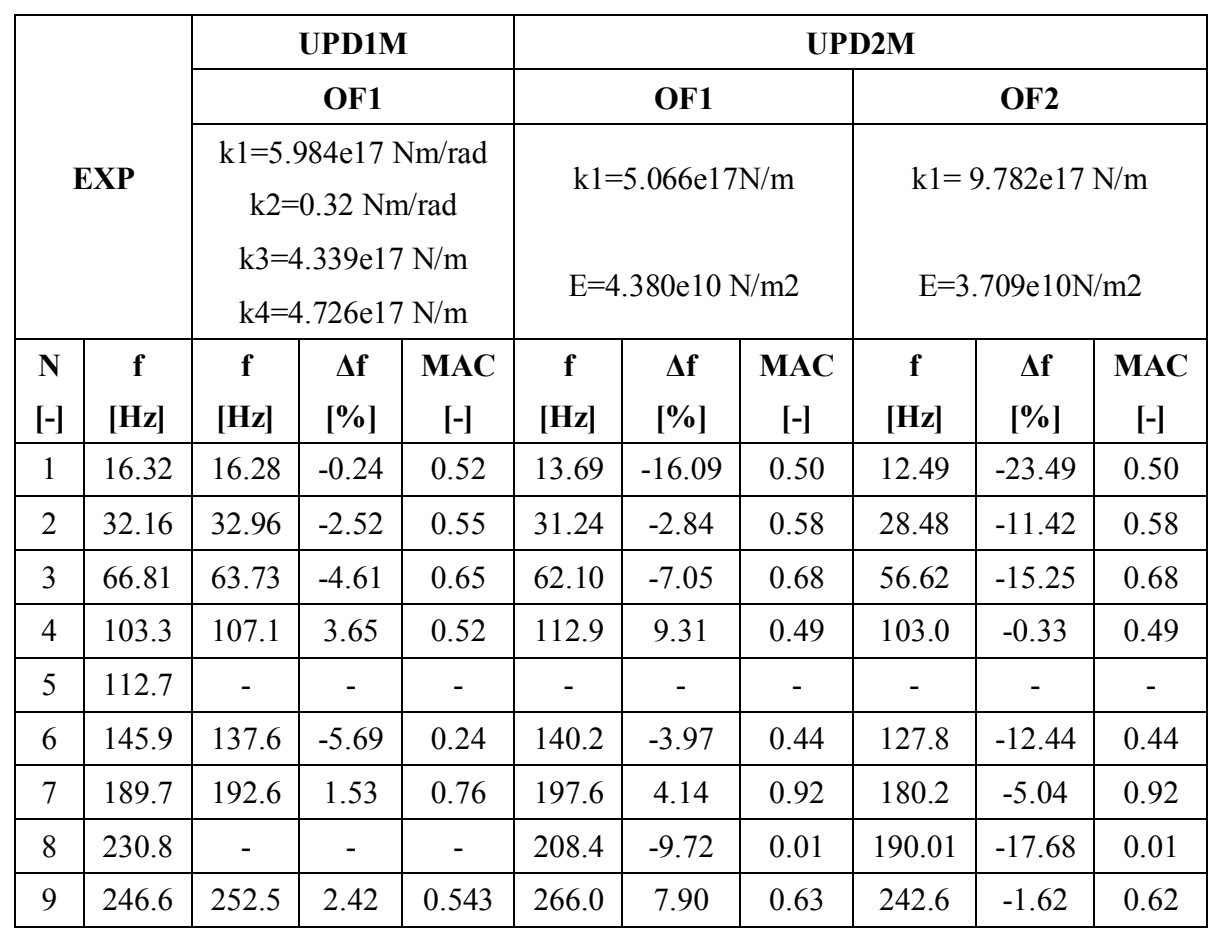

\section{Conclusions}

Updating of the frequencies results in a completely different model than assumed: no symmetry in the supports and a significant contribution of anti-rotation constraints. 
However the accuracy of obtained frequencies is satisfying. For UPD1M and OF1 the differences between corresponding frequencies does not exceed $6 \%$.

The presented updating do not consider the initial imperfection as well as the deformation caused by static load. This can be one of the reason of discrepancy of the results. Another potential reasons can be the material heterogeneity or reinforcement asymmetry.

The puzzling issue is the lack of compatibility of the mode shapes between numerical and experimental model. The similarity of modal forms was measured by MAC coefficient, which collecting the differences between all measurement directions in one value.

Due to the practical difficulties (arch is demanding structure) of precise locating of accelerometers and the character of measurements (as mentioned before, the measurements took place in parallel to a larger research project and had to respect location of the other sensors) the theoretical and actual location of accelerometers could differ a bit. Unfortunately, the arch was objectively small structure, so the influence of inaccuracy of location of sensors can be significant.

Finding the causes of inaccuracy of measurements and improving the model should be the goal of further research, but unfortunately the arch has already been destroyed in static examination and potential correction of position of accelerometers is impossible. However the conclusions from presented investigation will be used in future examination of similar structures.

\section{References}

1. O. S. Salawu, Eng. Struct., 19, 9 (1997)

2. M. Friswell, J.E. Mottershead, Finite Element Model Updating in Structural Dynamics 38, 1-286 (1995)

3. B. Miller, CAMES, 18, 191-203 (2011)

4. T. H. G. Megson, Structural and Stress Analysis, 130-145 (2014)

5. T. Uhl, W. Lisowski, Praktyczne problemy analizy modalnej konstrukcji, (1996)

6. T. Uhl, Komputerowo wspomagana identyfikacja modeli konstrukcji mechanicznych, (1997)

7. Global Optimization Toolbox User's Guide, MATLAB R2018a, (2018) 